\title{
Whether Alvarado scoring system is A Reliable Diagnostic Tool for Acute Appendicitis.
}

\author{
Haseeb Akbar ${ }^{1}$, Rida Fatima ${ }^{2}$, Tahoor Ahmed Khan ${ }^{3}$ \\ 1,2,3. House Officer Bahawal Victoria Hospital Bahawalpur
}

\begin{abstract}
: appendix.

DOI: $10.7176 / \mathrm{JMPB} / 55-15$

Publication date:May $31^{\text {st }} 2019$
\end{abstract}

Objective: to evaluate the diagnostic accuracy (discrimination) and implementation performance of Alvarado score. Methodology: This cross sectional study was done in Surgerical unit of Bahawal Victoria hospital Bahawalpur under supervision of consultant Surgeons of department. Study duration was 1 year from March 2018 to March 2019. For quantitative variables like age of patients Mean and SD was calculated, and frequency percentages were calculated for categorical data like gender. Negative appendectomy rate, positive predictive value, negative predictive value, sensitivity, specificity was calculated by using 2-2 contingency table. Results: Total 300patients enrolled in this study, both genders. Alvarado scoring at presentation, $15 \%(\mathrm{n}=45)$ patients were categorized into Group I. 13\% $(n=39)$ patients were included in Group II. While, 72\% $(n=216)$ were enrolled in Group III. Diagnostic test was positive in 223 patients. While, acute appendicitis was confirmed histo-pathologically in 160 patients. Gangrenous appendicitis observed in 3 patients. Chronic appendicitis, perforated appendicitis, appendicular abscess, no specific pathology, gangrenous intestine and salpingooophoritis was observed as $31,6,9,6,3$ and 5 respectively. There were 174 patients true positive, 49 were false positive, 59 were false negative and 18 were true negative. Sensitivity, specificity, negative predictive value and negative predictive value were $74.68 \% 26.87 \%, 78.02 \%$ and $23.37 \%$ respectively. Conclusion: Alvarado scoring system is useful tool in diagnosis of appendicitis in pre-operative period which can be useful for surgeons at any level of health care. According to our study observations Alvarado scoring system has better sensitivity $74.68 \%$ but specificity $26.87 \%$ which shows that Alvarado scoring system is helpful in diagnosis of appendicitis but not much helpful in preventing negative laparotomies.

Keywords: Right lower quadrant pain, Appendicitis scoring, Faecal peritonitis, Ultrasound abdomen, Perforated

\section{Introduction:}

Abdominal pain in right lower quadrant is most common presentation in surgical department and mostly diagnosed as acute appendicitis ${ }^{1}$. Appendicitis remains the most common surgical emergency which needs urgent referral and appendectomy before perforation (worse condition of appendicitis) ${ }^{2}$. First case of appendectomy was performed by an English army surgeon in 1935. He removes perforated appendix without any anesthesia. Un perforated appendicitis was removed successfully by Hencockin last years of $19^{\text {th }}$ century $^{3}$.

Pain in lower abdominal quadrant, fever, presence of leukocytosis and diffused peritonitis are the symptoms of acute appendicitis ${ }^{4}$. If clinical diagnosis is not clear wait for four to six hours and monitor the patient consistently, computed tomography is also helpful to improve diagnostic accuracy 5 . After complete observation if diagnosis is unclear and patient was discharged from hospital he should be advised for follow up within 24 hours or in case of symptoms reoccur ${ }^{6}$. There is noany contraindication of appendectomy if symptoms are present.

With these aspects of contraindication rate of negative appendectomy is much higher, about $20 \%$ negative appendectomy rate was reported in last few decades ${ }^{7}$. This much higher rate increases the cost of treatment, morbidity and mortality rate and poor outcomes of surgical intervention ${ }^{8}$. Abdominal ultrasound computed tomography and laparoscopic diagnosis was famous in earlier days. Another more advance and effective diagnostic method Alvarado scoring system was introduced on the basis of pure clinical history and signs/symptoms in $1986^{9}$. Alvarado is easy to perform and reliable than laboratory investigations. It consists of total 10 scores calculated after combining every symptom.

In this scoring system clinical predictions are helpful from signs and symptoms to target the accurate findings and diagnosis, laboratory investigations and radiological findings are some additional aspects. On the basis of these all findings and co-findings management and recommendations can be made which are helpful for better patients care and focused treatment ${ }^{9}$. 
Alvarado is a useful tool for eliminating the possible risks of patients presenting in emergency ward or in outdoor department with lower quadrant of abdomen in right $\operatorname{side}^{10}$. In our study we evaluate the diagnostic accuracy (discrimination) and implementation performance of Alvarado score.

\section{Methodology}

This prospective study was conducted in the department of general surgery Bahawal Victoria hospital Bahawalpur under supervision of senior surgeons of Department. Study duration was 1 year from March 2018 to March 2019. Study was started after ethical permission from hospital ethical committee and informed consent was obtained from patients who were included in the study. Non probability consecutive sampling technique was used and sample size was calculated by using confidence interval $95 \%$, power of study $80 \%$ and $\mathrm{P}$ (percentage of desired variable) negative appendectomy $59 \%$ taken from a previous study.

All patients who were presented with pain in right iliac fossa were included in the study irrespective of severity and signs of illness. Patients with already operated for appendicitis and who were refused to give consent were excluded from the study. Alvarado scoring was measured and documented by fourth year resident of general surgery. Patients were labeled in three groups, score one to four included in group I, five to six in group II and score seven to ten were included in group III.

Group I was treated as outpatient and asked for follow up after that, group II was kept under observation for 24 hours and treated with OS (Oshner-Shrian) treatment method and patients in group III treated on emergency basis. Specimen was taken from all patients for histopathological findings and to confirm the efficacy of Alvarado scoring system. Specificity, sensitivity, negative and positive predictive value and negative appendectomy was noted on pre designed Performa. Data was entered on computer software SPSS version 24 and analyzed for all possible variables. Mean and SD was calculated for numerical data variables like age of patients and frequency percentages were calculated for categorical data like gender. Negative appendectomy rate, positive predictive value, negative predictive value, sensitivity, specificity was calculated by using $2-2$ contingency table.

\section{Results:}

Total 300 patients enrolled in this study, both genders. Alvarado scoring at presentation, 15\% $(\mathrm{n}=45)$ patients were categorized into Group I. $13 \%(n=39)$ patients were included in Group II. While, $72 \%(n=216)$ were enrolled in Group III. The mean age of the patients in group I was $28.64 \pm 2.79$ years. There were $60 \%$ $(\mathrm{n}=27)$ males and $40 \%(\mathrm{n}=18)$ females. The mean age of the patients in group II was $28.74 \pm 236$ years. There were $64.1 \%(\mathrm{n}=25)$ males and $35.9 \%(\mathrm{n}=14)$ females. The mean age of the patients in group III was $28.74 \pm 2.72$ years. There were $62.5 \%(\mathrm{n}=135)$ males and $37.5 \%(\mathrm{n}=81)$ females. (Table. 1$)$.

Diagnostic test was positive in 223 patients. While, acute appendicitis was confirmed histopathologically in 160 patients. Gangrenous appendicitis observed in 3 patients. Chronic appendicitis, perforated appendicitis, appendicular abscess, no specific pathology, gangrenous intestine and salpingo-oophoritis was observed as $31,6,9,6,3$ and 5 respectively. There were 174 patients true positive, 49 were false positive, 59 were false negative and 18 were true negative. Sensitivity, specificity, negative predictive value and negative predictive value was $74.68 \% 26.87 \%, 78.02 \%$ and $23.37 \%$ respectively. (Table. $3 \& 4$ ). 
Table. 1

Demographic Characteristics among the study groups

\begin{tabular}{|c|c|c|c|}
\hline $\begin{array}{c}\text { Demographic } \\
\text { Characteristics } \\
\text { among the study } \\
\text { groups }\end{array}$ & $\begin{array}{c}\text { Group I, } \\
\mathbf{1 5 \%}(\mathbf{n}=\mathbf{4 5})\end{array}$ & $\begin{array}{c}\text { Group II, } \\
\mathbf{1 3 \%}(\mathbf{n}=\mathbf{3 9})\end{array}$ & $\begin{array}{c}\text { Group III, } \\
\mathbf{7 2 \%}(\mathbf{n}=\mathbf{2 1 6})\end{array}$ \\
\hline Characteristics & & & \\
\hline Age & $28.64 \pm 2.79$ years & $28.74 \pm 236$ years & $28.74 \pm 2.72$ years \\
\hline Gender & $\mathrm{M}=60 \%, \mathrm{~F}=40 \%$ & $\mathrm{M}=64.1 \%, \mathrm{~F}=35.9 \%$ & $\mathrm{M}=62.5 \%, \mathrm{~F}=37.5 \%$ \\
\hline
\end{tabular}

Table. 2

Alvarado scoring system

\begin{tabular}{|l|l|}
\hline \multicolumn{1}{|c|}{ Criteria } & \multicolumn{1}{|c|}{ Score } \\
\hline Symptoms & 1 \\
\hline Migratory RIF pain & 1 \\
\hline Nausea and vomiting & 1 \\
\hline Anorexia & \\
\hline Signs & 2 \\
\hline RIF Tenderness & 1 \\
\hline Fever & 1 \\
\hline Rebound RIF tenderness & \\
\hline Laboratory Tests & 2 \\
\hline Leukocytosis & 1 \\
\hline Neutrophilic Left Shift & $\mathbf{1 0}$ \\
\hline Total Score & \\
\hline
\end{tabular}


Table. 3

Operative findings and histopathology in the study

\begin{tabular}{|c|c|}
\hline Histopathology report & Frequency \\
\hline Acute appendicitis & 160 \\
\hline Gangrenous appendicitis & 3 \\
\hline Chronic appendicitis & 31 \\
\hline Perforated appendicitis & 6 \\
\hline Appendicular abscess & 9 \\
\hline No specific pathology & 6 \\
\hline Gangrenous intestine & 3 \\
\hline Salpingo-oophoritis & 5 \\
\hline Total & 223 \\
\hline
\end{tabular}

Table. 4

Observed indices in the study

\begin{tabular}{|c|c|c|c|}
\hline Diagnostic test result & $\begin{array}{c}\text { Confirmed } \\
\text { Appendicitis }\end{array}$ & No- Appendicitis & Total \\
\hline Positive & True positive (174) & False positive (49) & $\mathbf{2 2 3}$ \\
\hline Negative & False negative (59) & True negative (18) & $\mathbf{7 7}$ \\
\hline Total & $\mathbf{2 3 3}$ & $\mathbf{6 7}$ & $\mathbf{3 0 0}$ \\
\hline
\end{tabular}

Table. 5

Diagnostic Accuracy

\begin{tabular}{|c|c|}
\hline Diagnostic Measures & Value \\
\hline Sensitivity & $74.68 \%$ \\
\hline Specificity & $26.87 \%$ \\
\hline Positive Predictive Value (PPV) & $78.02 \%$ \\
\hline Negative Predictive Value (PPV) & $23.37 \%$ \\
\hline
\end{tabular}

\section{Discussion:}

In cases of acute appendicitis it is challenge for surgeons to make a right decision about surgery or accurate diagnosis especially in developing countries where there is limited assess of radiological investigations and other diagnostic techniques. Incidence of negative appendectomy is a major problem in such countries which was reported 25 to 45 in male and female genders. In our study we found negative appendectomy about $21 \%$, 
Sensitivity, specificity, negative predictive value and negative predictive value was $74.68 \% 26.87 \%, 78.02 \%$ and $23.37 \%$ respectively.

In a study conducted by Dunn et $\mathrm{a}^{11}$ in 1982 on this topic and reported diagnostic accuracy $75 \%$ while diagnostic accuracy of our study was $71 \%$ which almost similar. Results of this study were comparable with our results. In another study conducted by Lewis et al ${ }^{12}$ in 1975 and reported similar $75 \%$ diagnostic accuracy. These two studies strengthen our findings. Negative appendectomy rate of these two studies is also higher than previous studies.

Sensitivity was reported by Teicher et $\mathrm{al}^{13}$ in his study as 48 to $77 \%$ and specificity was 73 to $87 \%$, while sensitivity in our study was $74.68 \%$ and specificity $26.87 \%$. Sensitivity of our study is almost similar to that study but specificity is much lower. Lindberg et $\mathrm{al}^{14}$ also reported similar sensitivity as in study given above, in another study of Ramirez et $\mathrm{al}^{15}$ also reported similar findings. These all studies give favor to our study sensitivity vise but specificity vise these are against our findings.

In a study Kalan et $\mathrm{al}^{16}$ used another changed form of Alvarado scoring system and reported negative appendectomy in $14.6 \%$ of cases. When we concern about positive predictive value of our study was $78.02 \%$ in our study, in a previous study conducted by Jawaid A et $\mathrm{al}^{17}$ reported positive predictive value $97 \%$ which is comparable with our findings. Similarly Chan MY et al conducted similar study and reported $97.6 \%$ positive predictive value and Khan $\mathrm{I}$ et $\mathrm{al}^{18}$ reported $83.5 \%$. Negative appendectomy rate was reported $21,15.6$ and $7 \%$ in these reports. These all studies were comparable with our study.

Alvarado scoring system is a simple diagnostic method which can be modified easily by any surgical and non surgical health care provider ${ }^{19}$. In a study Koppad SN et $\mathrm{al}^{20}$ used Alvarado scoring system for evaluation of negative appendectomy rate and efficacy of Alvarado and reported negative appendectomy $5.9 \%$, sensitivity was $98.50 \%$ and specificity was $87.09 \%$. Similarly negative predictive value was $96.42 \%$ and positive predictive value was $94.36 \%$.

Conclusion: Alvarado scoring system is useful tool in diagnosis of appendicitis in pre-operative period which can be useful for surgeons at any level of health care. According to our study observations Alvarado scoring system has better sensitivity $74.68 \%$ but specificity $26.87 \%$ which shows that Alvarado scoring system is helpful in diagnosis of appendicitis but not much helpful in preventing negative laparotomies.

\section{References:}

1. Di Saverio S, Sibilio A, Giorgini E, Biscardi A, Villani S, Coccolini F. The NOTA Study (Non Operative Treatment for Acute Appendicitis): Prospective Study on the Efficacy and Safety of Antibiotics (Amoxicillin and Clavulanic Acid) for Treating Patients With Right Lower Quadrant Abdominal Pain and Long-Term Follow-up of Conservatively Treated Suspected Appendicitis. Ann Surg. 2014;260(1):109-117.

2. Robin B. Levenson, Katherine M. Troy, Karen S. Acute Abdominal Pain Following Optical Colonoscopy: CT Findings and Clinical Considerations. Am J Roentgenol. 2016;207(3):33-40.

3. Shogilev DJ, Duus N, Odom SR, Shapiro NI. Diagnosing Appendicitis: Evidence-Based Review of the Diagnostic Approach in 2014. West J Emergency Med. 2014;15(7):859-871.

4. Koppad, Sanjay N, Kodliwadmath, Harsha; DESAI, Mallikarjun. Analysis of application and diagnostic importance of Alvarado scoring system in patients with right lower quadrant abdominal pain. Inter Surg J. 2014;3(3): 1240-1243.

5. Flum DR. Clinical practice. Acute appendicitis--appendectomy or the "antibiotics first" strategy. N Engl J Med. 2015 May 14;372(20):1937-1943.

6. Netta M. Blitman, Muhammad A, KeriAnne B. Brady, Benjamin H. Value of Focused Appendicitis Ultrasound and Alvarado Score in Predicting Appendicitis in Children: Can We Reduce the Use of CT? Am J Roentgenol. 2015 204(6):707-712.

7. Zeki Özsoy, Erdinç Yenidoğan. Evaluation of the Alvarado scoring system in the management of acute appendicitis. Turk J Surg. 2017;33(3): 200-204.

8. Nain PS, Bhagtana A, Gill CS. Diagnostic Challenge of Acute Appendicitis: Appraisal through Modified Alvarado Score. MOJ Surg. 2017;4(5):00084. 
9. Golden SK, Harringa JB, Pickhardt PJ, Ebinger A, Svenson JE, Zhao YQ. Prospective evaluation of the ability of clinical scoring systems and physician-determined likelihood of appendicitis to obviate the need for CT. Emerg Med J. 2016;33(7):458-64.

10. Kollár D, McCartan DP, Bourke M, Cross KS, Dowdall J. Predicting acute appendicitis? A comparison of the Alvarado score, the Appendicitis Inflammatory Response Score and clinical assessment. World J Surg. 2015 Jan;39(1):104-109.

11. Dunn EL, Murphy JR. The unnecessary laprotomy for appendicitis:can it be decreased?Am Surg. 1982;48:320-3.

12. Lewis FR, Hocolt JW. Appendicitis: a critical review of diagnosis and treatment in 1000 cases. ArchSurg. 1975;110:677-84.

13. Teicher IRA,Cohen M. Soring system to aid in diagnosis of appendicitis.AnnSurg. 1983;198:753-9.

14. Lindberg G, Fenyo G. Algorithimic diagnosis of appendicitis using bayes theoramand logistic regression.in: bayesian statistics 3rd ed. Bernardo JM, Degroot MH. Proceedings if the third Valencia international meeting oxford: Clarendon Press;1988:665-668.

15. Ramirez JM, Dens J. Practical score to aid decision making in doubtful cases of appendicitis Br J Surj. 1994;81:680-3.

16. Kalan M. Evaluation of modified alvarado score in diagnosis of acute appendicitis a prospective study. Ann R CollSurjEngl. 1994;76:418-9.

17. Jawaid A, Asad A. Clinical scoring system a valuable tool for decision making in cases of acute appendicitis. J Pak Med Assoc. 1999;49(10);254-9.

18. Khan I ,Rehman A. Application of alvarado scoring in diagnosis of acute appendicitis .J Ayub Med Coll Abbottabad. 2005;17(3):41-4.

19. Denizbasi A, Unleur EE. The role of emergency medicine resident using the alvarado score in the diagnosis of acute appendicitis copmpared with emergency general surgery rsidentEur J Emerg Med. 2003;10(4):296-301.

20. Koppad SN, Kodliwadmath H, Desai M. Analysis of application and diagnostic importance of alvarado scoring system in patients with right lower quadrant abdominal pain. Int Surg J 2016;3:1240-3. 